\title{
Intuição e causalidade na crítica de Schopenhauer à epistemologia kantiana
}

\author{
Intuition and causality in Schopenhauer's criticism of Kant's epistemology
}

\author{
Jaqueline Engelmann*
}

Resumo: Pode-se afirmar que a filosofia crítica kantiana é uma espécie de suporte para a fundamentação epistemológica de Schopenhauer, mas que a teoria schopenhaueriana de modo algum a ela se reduz até porque Schopenhauer reprova desde a compreensão de Kant a respeito do papel que desempenham intuição e razão até a arquitetônica kantiana que exige doze categorias como alicerce do processo de conhecer. Nosso texto versará sobre a importância que Schopenhauer concede à intuição e, principalmente, sobre a justificação de Schopenhauer acerca da causalidade como única "categoria" necessária e suficiente para a percepção dos objetos.

Palavras-chave: Causalidade; Intuição; Entendimento; Categorias; Crítica; Epistemologia

Abstract: One may assume that Kant's philosophical criticism is a kind of basis for Schopenhauer's own epistemological foundation. Nonetheless one can find out that Schopenhauer's theory is not to be reduced to that basis and even rejects a large amount of it. Schopenhauer disagrees completely with what Kant means by intuition and reason as far as it led the latter to postulate twelve categories as an architectural condition for human knowledge. This paper is a discussion about the relevant role of intuition according to Schopenhauer and, first of all, Schopenhauer's argument about causality as the only necessary and sufficient "category" for perceiving objects.

Keywords: Causality; Intuition; Understanding; Categories; Criticism; Epistemology

\section{Conhecimento intuitivo em Schopenhauer}

"Que é conhecimento? - Ele é primária e essencialmente representação. - Que é representação? - Um complexo processo fisiológico no cérebro de um animal ao fim do qual se tem a consciência de uma imagem" (W II, p. 232). Esta breve passagem, que aparece logo no início do capítulo 18 do Tomo II de $O$ mundo como vontade e representação, é assaz rica para a abertura de uma análise acerca da compreensão schopenhaueriana do processo de obtenção de conhecimento que - como ilustra a passagem - até certa medida não é prerrogativa exclusiva do homem, mas que este compartilha com outros animais. A compreensão deste processo envolve, necessariamente, a noção de representação inaugurada por Schopenhauer ${ }^{1}$.

Para Schopenhauer, representação e objeto são indissociáveis, são uma e mesma coisa, ou seja, não há objetividade alguma para além do objeto percebido, pois todo objeto não é nada além de representação. A tese de Kant é, quanto a isso, significativamente distinta: o que Kant chama de conhecimento fenomênico é algo que depende, de algum modo, de um objeto transcendental que ultrapassa a possibilidade de experiência do sujeito humano, mas ainda assim é apresentado como "objeto". Embora Kant afirme que esse objeto, a coisa em si, não pode ser conhecido, defende que deve ser necessariamente admitido. Porém, para Schopenhauer, tal objeto não seria sequer pensável, pois todo objeto, como tal, supõe um sujeito que o perceba, de maneira que uma coisa em si,

\footnotetext{
${ }^{1}$ Não pretendemos com tal afirmação sugerir que Schopenhauer tenha sido o primeiro a trazer o termo "representação" para o contexto de compreensão da teoria do conhecimento. Porém, com Schopenhauer, a noção de representação ganha novo significado e valor na medida em que não é correlato de um objeto real em si mesmo, independente do próprio conhecimento.
}

* Professora Associada de Filosofia no Instituto Federal de Educação, Ciência e Tecnologia do Rio Grande do Norte, Natal, RN. Email: jqengel@gmail.com ORCID: https://orcid.org/0000-0002-49336-4396 
propriamente dita, não pode ter nenhuma relação com isso ${ }^{2}$. Em sua dissertação de mestrado, Maria Lúcia Cacciola esclarece de modo coeso essa diferença por nós apontada entre a noção kantiana de representação e aquela formulada por Schopenhauer:

Tanto o fenômeno em Kant, quanto a representação em Schopenhauer se referem a uma dependência com relação às formas do sujeito. No entanto, quando Schopenhauer constrói o mundo como representação ou o mundo objetivo, o faz com a ressalva de que nada "de fora" afeta o sujeito. Não se trata, como em Kant, de uma "afecção dos nossos sentidos por algo desconhecido (etwas unbekanntes)", mas de uma sensação cega que não remete a nada. Tendo em vista a pobreza da matéria fornecida pela sensação, é tarefa do entendimento constituir a representação ou o objeto ${ }^{3}($

Apesar de a sensação ser "cega" em Kant, a intuição também o seria até que o entendimento, aplicando suas categorias a esse obscuro objeto, lhe conferisse "materialidade". Toda matéria é, para Schopenhauer, como em Kant, um objeto intelectual, não podendo nos ser dada pela mera sensação, pois é o entendimento a representá-la como estando fora de nós segundo a forma do espaço. Para Schopenhauer, a realidade empírica, enquanto representação, é da mesma natureza do sonho. Neste sentido, o encantamento que sentimos ao ler $O$ Mundo é deveras semelhante àquele que sentimos ao ler La vida es sueño, de Calderón de la Barca. O mundo sonhado e o mundo real provêm de uma mesma forma - embora sejam diferentes pelo seu conteúdo - e esta forma é fornecida pelo intelecto, enquanto uma função do cérebro. O próprio Schopenhauer nos apresenta essa metáfora: sonho e vida são um e mesmo livro, só que lido de maneiras diferentes ${ }^{4}$. Por isso, o objeto deve sempre ser representação, ele é sempre intelectual, o mundo conhecido existe apenas como representação. Para Kant, porém, na Crítica da razão pura, a intuição capta imediatamente aquilo que é $d a d o$ à sensibilidade, ou receptividade da intuição ${ }^{5}$, sempre de maneira indeterminada. Para além disso, a pressuposição de que os objetos são dados à intuição e que ela é responsável por captar essa difusa representatividade implica, também, na concepção kantiana, que nossas intuições são sempre meramente sensíveis, cegas.

Nesse ponto, Schopenhauer reconhece um contrassenso, pois não se pode falar em intuição na ausência de um objeto percebido de maneira determinada como algo presente aos sentidos, um objeto empírico real, tal como o define o próprio Kant. Por conseguinte, o entendimento, como faculdade pela qual os objetos da percepção são determinados, não pode ser considerado uma faculdade distinta da intuição. Esta, por sua vez, não é apenas sensível, como em Kant, mas, especialmente, intelectiva. Em torno dessa elucidação é que deveremos nos deter por mais tempo.

O mundo da experiência (fenomênica) é construído pelas nossas intuições. O sujeito, portanto, é a condição de existência de todo e qualquer objeto. O próprio corpo do sujeito de conhecimento é uma construção na medida em que o intelecto o representa como afetado por causas externas, fazendo uso das formas de tempo, espaço e causalidade. Aliás, como muito bem analisado por Eduardo Fonseca em Uma estreita passagem, o corpo é o primeiro motor de nossa capacidade de percepção, ou seja, só há percepção objetual a partir do sentimento do próprio corpo de modo que, afirma Fonseca, "o conhecimento intelectual resulta da influência exercida pelos dados

\footnotetext{
${ }^{2}$ Isso significa que, apesar de Schopenhauer afirmar que o grande mérito da filosofia crítica kantiana foi ter realizado a devida distinção entre fenômeno e coisa em si, ambos não compreendem fenômeno e coisa em si do mesmo modo.

${ }^{3}$ CACCIOLA, a crítica da razão no pensamento de schopenhauer, P8

${ }^{4}$ Como bem recorda Lefranc, essa tese schopenhaueriana que afirma que a vida é sonho não é devedora, em nada, à distinção que Kant estabelece entre ilusão e fenômeno dado que um idealismo bem fundamentado e bem compreendido sequer se coloca o problema da realidade do mundo exterior. Não há nenhuma necessidade de "revelação", pois ninguém está brincando de esconde-esconde conosco, nem Deus, nem o demônio, nem o gênio maligno de Descartes, conclui de forma quase poética Lefranc.

5 "Seja de que modo e com que meio um conhecimento possa referir-se a objetos, o modo como ele se refere imediatamente aos mesmos e ao qual todo pensamento como meio tende, é a intuição. Esta, contudo, só ocorre na medida em que o objeto nos for dado." (KANT, Crítica da razão pura, 71 [B 33]).
} 
exteriores junto ao corpo", dados esses determinados como exteriores pela atividade do entendimento, ou seja, por um sujeito de conhecimento ${ }^{7}$. É em Schopenhauer, contudo, mais especificamente no capítulo inicial do Tomo II de $O$ Mundo, que encontramos uma rica passagem que esclarece essa relação entre o corpo como aquilo por meio de que o sujeito conhece (objeto imediato) e como aquilo que pode ser conhecido pelos sentidos (objeto mediato), ou seja, ele mesmo como representação e como mediador para outras representações. Ao abordar a polêmica em torno da "idealidade de todo objeto", Schopenhauer mostra a diferença entre o próprio corpo e os demais corpos, ambos objetos, e a irredutibilidade do sujeito propriamente dito a esses fenômenos:

[...] aquele outro, de quem considero agora a minha pessoa como o seu objeto, não é em verdade o sujeito, mas, antes, um indivíduo que conhece. Por isso, ainda que aquele outro não existisse, até mesmo se não houvesse outro ser que conhecesse senão eu mesmo, nem por isso seria suprimido o sujeito, em cuja representação apenas existem todos os objetos. Pois esse sujeito sou também eu mesmo, bem como qualquer ser que conhece. Por conseguinte, no caso admitido, minha pessoa continuaria a existir, mas de novo como representação, a saber, em meu próprio conhecimento. Pois minha pessoa é também por mim mesmo conhecida, apenas mediata e nunca imediatamente, já que todo ser-representação é algo mediato. De fato, eu conheço meu corpo como objeto, ou seja, como extenso, preenchendo o espaço e fazendo efeito, tão somente na intuição de meu cérebro: esta é mediada pelos sentidos, com cujos dados o entendimento que intui executa a sua função, que é passar do efeito à causa e, assim, na medida em que o olho vê o corpo, ou as mãos o tocam, constrói a figura espacial que se expõe no espaço como meu corpo (W II, 1, 7 [trad. br. 8]).

A passagem por nós escolhida é deveras longa, mas indispensável a esta análise porque concentra nela mesma quase que, poderíamos dizer, um apanhado geral da epistemologia schopenhauriana pelo fato de que remete à compreensão não apenas da noção de representação, mas também de sua relação com o corpo do sujeito que conhece e - mais importante ainda - é também uma explicação do processo a partir do qual resultam as representações, ou seja, da relação entre nossas intuições e o entendimento a partir das formas de tempo, de espaço e de causalidade. Para além disso, é justamente na compreensão desse processo que encontraremos o núcleo da crítica de Schopenhauer a Kant.

Enquanto Kant estabelece um muro divisório entre conhecimento intuitivo e conhecimento intelectual ${ }^{8}$, relacionando o último à faculdade discursiva, puramente racional, e, o primeiro, à estrita sensibilidade pura, Schopenhauer afirma a indissociabilidade de intuição e entendimento.

\footnotetext{
${ }^{6}$ FONSECA, Uma estreita passagem, 41.

7 Aqui se verifica, em primeiro lugar, que o próprio corpo desempenha um papel preponderante na relação de conhecimento com outros objetos, mas não se confunde com o sujeito que conhece. $\mathrm{O}$ fator que a tantos confunde e tantos mal entendidos já produziu consiste justamente em que o sujeito precisa ser dotado de um corpo para perceber objetos, mas esse mesmo corpo já é um objeto percebido mediante a afecção produzida nele por outros objetos, sem o que o sujeito não teria nenhuma consciência, nem de outras coisas, nem de si mesmo. Por isso, Schopenhauer afirma que sujeito e objetos são indissociáveis, um existe exclusivamente em relação ao outro, não sendo possível declarar que qualquer deles tenha existência separada. Cacciola, em A questão do dogmatismo, traz à tona essa discussão também conhecida como "paradoxo de Zeller" e o próprio Schopenhauer a denomina "antinomia da faculdade de conhecer". Porém, torna-se um paradoxo apenas na medida em que tratamos, nos mesmos termos, a realidade empírica e a idealidade transcendental. Contudo, esse tópico de discussão - a questão do corpo e sua representabilidade - é, por si só, um tema bastante vasto e interessante que, por não se tratar de uma questão central em nossa análise, não será aqui aprofundado. Sugerimos a leitura de Uma estreita passagem: o conceito de corpo nas obras de Schopenhauer e Freud para uma melhor compreensão do problema.

${ }^{8}$ A conferência de Lebrun sobre Kant, intitulada $O$ subsolo da crítica, recorda bem este tópico da separação do sensível e do intelectual em Kant através do adágio "nunca macular os inteligíveis", ou seja, já na Dissertação de 1770, Kant enfatizou a necessidade de dar atenção ao conhecimento sensível de modo a não permitir que ele ultrapasse os seus limites para que não possa, assim, macular os inteligíveis. Não é diferente na Crítica da razão pura, quando Kant acusa Leibniz de não distinguir as duas fontes de conhecimento: sensibilidade e intelecto.
} 
Para Kant, nossas intuições são sempre sensíveis, oriundas de nossos órgãos sensoriais e dependentes das intuições puras, tempo e espaço, incapazes de dar unidade à sua característica multiplicidade. Já o entendimento é, para Kant, uma faculdade intelectual a partir da qual obtemos, via de regra, conhecimento que, por sua vez, tem de ser determinado segundo a unidade conceitual. Dito de outro modo, o conhecimento propriamente dito reside no pensamento por conceitos (abstratos, como são todos os conceitos, segundo Schopenhauer) preenchidos pelos dados da sensibilidade, o que se encontra expresso na sentença kantiana: intuições sem conceitos são cegas, conceitos sem intuições são vazios. Sem sombra de dúvidas, Schopenhauer concorda com a segunda parte: não existem conceitos sem intuições. Porém, não pode concordar com a primeira, dado o privilégio que ele concede ao conhecimento intuitivo.

$\mathrm{Na}$ epistemologia schopenhauriana é perfeitamente clara a compreensão de que os órgãos sensoriais nos fornecem apenas sensações, nunca intuições, apesar de intuições empíricas requererem material sensível, condição de sua realidade, distinguido-as de meras ilusões. Portanto, como já afirmamos anteriormente, para Schopenhauer não existem intuições meramente sensoriais. As intuições são sempre determinadas intelectualmente no sentido de que dependem da aplicação da lei de causalidade, mas esta, como vimos, pertence à intuição, não à faculdade de pensar, como defendeu Kant. A simples sensação não produz representação alguma, tão somente uma "consciência abafada" como aquela que se atribui às plantas. Salviano, citando Schopenhauer, auxilia fortemente no esclarecimento acerca da inexistência de qualquer intuição a partir, pura e simplesmente, de nossos órgãos sensoriais:

Pensar que a sensibilidade por si só nos dá o mundo pronto e acabado, tal como ele existe em si, é recair no empirismo, que Schopenhauer rejeita: é como acreditar que esta mesa com todo o seu conteúdo pulasse para dentro de minha consciência no momento mesmo em que a vejo. Os sentidos são excitados pelo objeto externo (luz, som, odor) oferecendo a sensação: "a modificação que os sentidos recebem de uma tal impressão não é ainda uma intuição, mas apenas a matéria [Stoff] que o entendimento transforma em intuição". O entendimento ou inteligência - faculdade comum a toda a animalidade - tem como função relacionar o efeito (impressões corporais) à causa (representação) ${ }^{9}$.

É muito importante notar que essa diferença pontual entre as epistemologias de Kant e Schopenhauer carrega implicações decisivas para a adequada compreensão do quanto os dois filósofos se encontram afastados um do outro sob diversos aspectos. Pode parecer supérfluo insistir no fato de que intuições não possam ser meramente sensoriais, como pretendiam os empiristas, se ambos os filósofos distinguem sensação de intuição, mas o que verdadeiramente está em jogo é que: se Kant pretendia refutar toda a possibilidade de uma intuição intelectual, ou seja, de um entendimento que intui e sem recorrer à sensibilidade, sendo esse um dos pontos centrais da Analítica Transcendental, Schopenhauer, por sua vez, pretendia, embora partindo dos princípios críticos kantianos, defender, ao mesmo tempo, um entendimento intuitivo cuja atividade não se confundisse com o que defendiam os advogados da intuição intelectual, em seu tempo ou anteriores a Kant, os quais, no fundo, tratavam de uma intuição pura da razão, como se o sujeito do conhecimento pudesse subsistir como substância independente de objetos reais.

As formas de toda representação são intelectuais, ou seja, são aplicadas pelo cérebro e não se encontram nos órgãos sensoriais. A intelectualidade da intuição é inegável em Schopenhauer porque todo objeto conhecido é representação de um intelecto. Em outras palavras, como os sentidos não produzem objetividade alguma, é somente com o envolvimento do órgão cerebral, através de uma sua função - que Schopenhauer denomina "intelecto" - que é possível intuir e, portanto, conhecer. Essa faculdade é compartilhada por todos os animais em algum grau, pois a lei de causalidade opera em todo intelecto, mesmo que desprovido de razão, o que se constata mediante a ação dos animais segundo a

${ }^{9}$ SALVIANO, O fundamento epistemológico da metafísica da vontade de Arthur Schopenhauer, 110. 
representação de motivos, não de maneira pura e simplesmente cega ${ }^{10}$. Em outras palavras, à diferença de Kant, em Schopenhauer temos a independência da faculdade do entendimento em relação à racionalidade ${ }^{11}$. No mundo animal, intuições existem de forma totalmente independente da racionalidade, pois esta não os acompanha, enquanto que, no homem, intuições não dependem de conceitos, apesar da racionalidade ser uma constituição sua. Como foi afirmado anteriormente, tal independência não é uma via de mão dupla, pois conceitos sem intuições são vazios, mas intuições ocorrem sem dependência alguma da faculdade de abstração, nunca são cegas como a mera sensibilidade incapaz de representação em sentido estrito, ou seja, privada de consciência.

\section{Entendimento e racionalidade}

Uma possível tentativa de conciliação entre as teorias do conhecimento de Kant e de Schopenhauer teria que passar, mais uma vez, pela adequação do conceito de entendimento, pois o que Schopenhauer assume como pressuposto é que, de fato, sensações sem entendimento são cegas, mas isso não significa que precisem estar submetidas a conceitos, uma vez que o conteúdo da intuição empírica é material sensível tal como determinado pelo intelecto. Cacciola esclarece, mais uma vez, a questão da intelectualidade da intuição schopenhaueriana por meio da seguinte passagem: "Se, como exige Schopenhauer, pensar e intuir devem estar nitidamente separados, sendo intuição, por si só capaz de produzir conhecimento, ela não será meramente receptiva, mas nela já tem que se efetivar a potência do entendimento. Tem-se assim a intuição intelectual" 12 . O mundo intuitivo é, para Schopenhauer, de uma riqueza inestimável e incomparável em relação ao mundo conceitual, pois nele se encontra todo o conteúdo, material ou formal, de nosso conhecimento, o qual a razão, ou pensamento abstrato, só pode acessar a posteriori, por reflexão. A certeza, a legalidade que provém da faculdade de razão é - apesar disso e talvez por isso - sempre restrita em relação às possibilidades representacionais da intuição, tal como o próprio Kant demonstra na Analítica e na Dialética Transcendentais. Em sua dissertação, Cacciola, não obstante, sinaliza o importante ponto de corte de Schopenhauer em relação a Kant: "É na relação entre pensar e intuir e na primazia que um ou outro adquirem no processo do conhecimento que se manifesta o modo pelo qual Schopenhauer se desvia de Kant, propondo nova solução para o problema da constituição do mundo da experiência" ${ }^{13}$. Trata-se, em última análise, do papel do entendimento e de seu modo de atuação em cada caso. Sendo assim, a questão fundamental que diferencia

\footnotetext{
${ }^{10}$ Para quem já se dedicou a observar um cão ou um gato, por exemplo, tal manifestação intelectual, ou seja, a determinação dos movimentos pela lei de motivação se mostra bastante evidente. Logo no início do capítulo 5 dos Suplementos ao primeiro livro, intitulado Do intelecto desprovido de razão, podemos ler: "Os animais têm entendimento, sem terem faculdade de razão, portanto, têm conhecimento intuitivo, mas não abstrato: apreendem corretamente, também captam imediatamente o nexo causal, e os animais superiores o captam inclusive através dos vários elos da cadeia causal; contudo, propriamente dizendo, não pensam. Pois lhes faltam os conceitos, isto é, as representações abstratas. A consequência mais direta disso é a falta de uma verdadeira memória, de que carecem até mesmo os mais inteligentes dentre eles, e justamente isto fundamenta a principal diferença entre a sua consciência e a humana." (W II, 62 [trad. br. 69]).

${ }^{11} \mathrm{Na}$ Crítica da filosofia kantiana, Schopenhauer analisa todas as passagens da Crítica da razão pura, mais especificamente, da Analítica Transcendental, nas quais Kant ou toma entendimento e razão como sinônimos ou então modifica ao longo do texto o sentido destinado às noções de entendimento e de razão. Tal análise pormenorizada pode ser lida em $O$ Mundo: “O entendimento é também sempre redefinido de modo novo em sete passagens da $C r i ́ t i c a$ da razão pura. Na p.[A] 51 (V [B], 75) é a faculdade de produzir representações elas mesmas; na p.[A] 69 (V [B], 94) é a faculdade de julgar, ou seja, de pensar, isto é, conhecer por conceitos; na p.[B] 137, quinta edição, é genericamente a faculdade de conhecimento, na p.[A] 132 (V [B], 171) é a faculdade das regras, porém na p.[A] 158 (V [B], 197) é dito que ele 'não é somente a faculdade das regras, mas a fonte dos princípios fundamentais segundo a qual tudo se encontra sob regras', e, não obstante, fora anteriormente oposto à razão, porque exclusivamente esta seria a faculdade dos princípios; na p.[A] 160 (V [B], 199) o entendimento é a faculdade dos conceitos, mas na p.[A] 302 (V [B], 359 ) é a faculdade da unidade das aparências por meio de regras" (W I, 513 [trad. br. 502]).

${ }^{12}$ CACCIOLA, A crítica da razão no pensamento de Schopenhauer, 51.

${ }^{13}$ CACCIOLA, A crítica da razão no pensamento de Schopenhauer, 6.
} 
Schopenhauer de Kant reside na defesa por parte do primeiro de que a sensibilidade pura nada intui e nada representa, mas o que nos dá o entendimento, o conhecimento puro a priori da causalidade, nada mais é do que a unidade daquilo que Kant havia denominado formas da sensibilidade (tempo e espaço), tal como demonstrado em $O$ Mundo, §4. A crítica adquire sua maior clareza e concisão no seguinte trecho:

\begin{abstract}
Mas, do mesmo modo que o objeto só existe para o sujeito como sua representação, também cada classe especial de representações existe só para uma igualmente especial disposição do sujeito, que se nomeia faculdade de conhecimento. O correlato subjetivo do tempo e espaço neles mesmos, como formas vazias, Kant denominou sensibilidade pura, expressão que pode ser conservada, pois Kant abriu aqui o caminho, embora tal expressão não seja apropriada visto que a sensibilidade já pressupõe a matéria. O correlato subjetivo da matéria, ou causalidade, pois ambas são uma coisa só, é o entendimento, que não é nada além disso (W I, 13).
\end{abstract}

Evidentemente, Schopenhauer não entende a função da faculdade de entendimento da mesma forma que Kant - como procuramos esclarecer anteriormente -, mas, além disso, a noção de "entendimento" tem, para um e outro, significados distintos. Para Kant, trata-se de uma faculdade da razão, por vezes sendo a mesma, noutras desempenhando papel semelhante - pensar, julgar -, mas sempre responsável pela síntese conceitual. Para Schopenhauer, o entendimento é uma função de nosso cérebro que atua na origem do ato de conhecer. Assim sendo, ao defender a intelectualidade da intuição, a posição de Schopenhauer não pode ser confundida com a do idealismo absoluto alemão, dado que a noção é concebida de modo totalmente diverso: o processo intelectual que ocorre no cérebro nada mais é do que o conhecimento da causalidade produzindo a percepção objetual como a de um corpo presente no espaço externo mediante uma modificação no tempo sentida internamente. Nas palavras de Schopenhauer: "A primeira e mais simples aplicação, sempre presente, do entendimento é a intuição do mundo efetivo: este nada é absolutamente senão conhecimento da causa a partir do efeito: por conseguinte, toda intuição é intelectual" (W I, 13). A mera sensibilidade não produz nada para além de um sentimento cego, sem conteúdo, e é nesse sentido que podemos afirmar que o conhecimento intuitivo depende do intelecto, ou melhor, intuições são, para Schopenhauer, sempre oriundas do intelecto.

A mais originária representação de algo - por mais precária que seja - depende da lei de causalidade tal como conhecida a priori, não mais como "categoria", mas como correlato subjetivo da matéria, da efetividade de um objeto representado como algo exterior ao sujeito, uma concepção de "matéria" que, a rigor, não se distingue substancialmente do que diz Kant na Crítica da razão pura. Essa importante observação permite entender o quão original é a epistemologia schopenhaueriana pois foi ele o primeiro a afirmar que a faculdade do intelecto não é prerrogativa humana, mas era assim mantida por Kant na medida em que fazia do entendimento uma faculdade de pensamento. Eis um exemplo do quão distante se encontram os autores por trás de semelhanças pontuais. Os animais também intuem, segundo Schopenhauer, e possuem intelecto que opera tal qual nos humanos, ou seja, pela conformação das percepções à lei de causalidade. O que distingue humanos de animais é a faculdade de abstração, a razão que formula conceitos e os ordena a partir da representação intuída pelo entendimento. Quem também esclarece essa questão tão controversa, qual seja, a intelectualidade da intuição em Schopenhauer, é Ciolino: "A ideia schopenhaueriana da intelectualidade da intuição empírica responde primariamente à plausibilidade empírica de uma teoria do conhecimento que contemple as condições de possibilidade de uma interação representacional e intencional com a realidade externa em geral" ${ }^{14}$.

Sem a participação do entendimento na intuição, nenhuma representação do mundo é possível, tampouco o mundo objetivo é possível. Como bem enfatiza Cacciola, intuir o mundo real significa conhecer o efeito que aponta necessariamente para uma causa, ou seja, conhecer o efeito (a partir do próprio corpo, da própria sensibilidade) mediante a aplicação da lei de causalidade. Desta

${ }^{14}$ CIOLINO, Schopenhauer e il fondamento della conoscenza, 82. 
forma, são responsáveis pela obtenção do conhecimento a intuição, que só é possível porque ocorre no intelecto que opera segundo o princípio de razão, que, por sua vez, faz uso das formas do espaço, do tempo e da causalidade. Debona também descreve, de modo bastante profícuo, esse processo que ocorre no cérebro, tanto dos humanos quanto dos animais - de maneira particularmente visível naqueles que possuem suficiente grau de "inteligência" (que é o caso de, principalmente, mamíferos como cachorros, gatos, elefantes, macacos). Vale aqui enfatizar que, para Schopenhauer, um intelecto mais desenvolvido torna mais clara a sua capacidade de representação - há apenas diferenças de grau entre diferentes animais e humanos:

Por isso, o contato dos órgãos sensoriais com a matéria ainda não é representação, mas são apenas dados. As sensações são conduzidas até o intelecto para que, assim, o entendimento possa agir e, daí sim, as representações intuitivas possam existir. No processo de "elaboração mental" para a definição de uma imagem o individuo é ativo, e possui três formas puras e inatas de conhecimento para poder captar o mundo que o circunda: o tempo, cuja essência é a sucessão; o espaço, cuja essência é somente a posição; e a causalidade, que está sempre buscando a origem dos fenômenos. Essas formas fazem parte do chamado Satz vom Grund, princípio de razão ${ }^{15}$.

O princípio de razão, extensivamente investigado por Schopenhauer em Sobre a quadrúplice raiz, assume quatro formas: 1) princípio de razão suficiente do devir: determina as representações da realidade empírica, intuitivas; 2) princípio de razão de conhecer: relativo às representações conceituais, abstratas; 3) princípio de razão de ser: a ele se remetem as intuições puras de espaço e tempo, o fundamento das matemáticas; 4) princípio de razão suficiente do agir: rege a determinação das ações humanas ou animais por motivos.

A distinção schopenhaueriana entre as modalidades do princípio de razão não tem apenas uma justificativa epistemológica, mas, antes disto, reflete sua postura metafísica, dado que, através da distinção, por exemplo, entre princípio do devir e do conhecer, Schopenhauer estabelece sua postura antidogmática. Conforme Schopenhauer, toda representação é sempre relativa a alguma forma do princípio de razão. A representação é mediada pelos órgãos sensoriais e pelas condições intelectuais da experiência, ou seja, pela intuição que opera através do entendimento (ou cérebro, quando considerado do ponto de vista objetivo/material). Enquanto princípio a priori de todo conhecimento por representação, o conhecimento da lei de causalidade não pressupõe experiência alguma, sendo, como em Kant, um conhecimento de natureza inteiramente distinta das meras associações a posteriori entre fatos sucessivos que levara ao chamado "problema de Hume". Nesse sentido, Schopenhauer segue a crítica de Kant ao defender que, ao invés de apreendido da experiência, o conhecimento da lei de causalidade, a que toda mudança está submetida, é condição transcendental de toda experiência. Todavia, Schopenhauer critica de modo contundente a dedução kantiana das categorias em geral e, especialmente, da categoria de causalidade. Cacciola aborda o assunto detalhando o argumento desenvolvido por Schopenhauer em um longo trecho acrescentado à segunda edição da Dissertação sobre o princípio de razão, de 1847:

Schopenhauer salienta ainda a necessidade de provar tanto que a causalidade é independente da experiência e portanto "a priori", como também que a intuição já a pressupõe. É para esta via que conduziram as reflexões já mencionadas e que se complementam através das considerações sobre a lei da causalidade, expostas [sobretudo na segunda edição] na Dissertação sobre o Princípio de Razão. Aí, além de uma demonstração do caráter apriorístico da causalidade e da intelectualidade da intuição, Schopenhauer critica a prova de Kant do apriorismo da lei causal como insuficiente. [...] a lei causal como função própria do entendimento não poderá ter a mesma origem que a lei que vige em relação às representações abstratas, que é o princípio de razão do conhecer. Garantir o domínio de um conhecimento intuitivo, cuja possibilidade independa totalmente do

${ }^{15}$ DEBONA, Schopenhauer e as formas da razão, 33-34. 
conhecimento racional, é a preocupação fundamental que norteia a prova do apriorismo da lei causal. É no § 21 da Dissertação sobre o Princípio de Razão [da segunda edição, de 1847] que está exposta a constituição do princípio de razão suficiente do devir, ou lei da causalidade ${ }^{16}$.

Trata-se, fundamentalmente, de não confundir o conhecimento a priori da causalidade, sob a rubrica kantiana de "categoria" (conceito-predicado), com o conhecimento de conceitos puros a priori. Se, para Schopenhauer, baseando-se na tradição, conceitos são tomados por abstrações, produtos secundários da atividade mental de seres racionais, não pode, consequentemente, admitir que haja conceitos a priori, tampouco conceitos puros, cuja noção soa, no mínimo, obscura para Schopenhauer. Mesmo o princípio de razão de conhecer não supõe o conhecimento a priori de conceitos independentes da experiência, mas consiste em determinações que regem a priori a formulação de conceitos e suas relações em juízos, como, por exemplo, as leis formais do silogismo, nas quais se deve notar que não estão em jogo os conteúdos, apenas as formas das relações entre juízos.

Exposta a distinção entre os âmbitos intuitivo e abstrato do conhecimento humano, passamos à análise mais detida do ponto central da polêmica de Schopenhauer contra Kant, ou seja, que basta o conhecimento a priori da causalidade para que o entendimento conheça, dispensandose, portanto, as outras onze categorias elencadas por Kant.

\section{A suficiência da causalidade para a percepção dos objetos}

Os objetos sensíveis, perceptíveis por meio dos sentidos externos, são aqueles que podemos chamar "materiais". A matéria em geral, na medida em que é de fato percebida, ou seja, enquanto não é tomada abstratamente como uma substância, se apresenta a cada um, de acordo com Schopenhauer, como causalidade. Isso significa que o material sensível não é algo produzido, um efeito, mas aquilo mesmo que se percebe mediante a aplicação, pelo entendimento, da lei de causalidade $^{17}$. Tal lei, como vimos, é responsável por gerar determinada representação intuitiva, a consciência de um objeto real posto no espaço externo. Sendo assim, o autor de $O$ Mundo assume que apenas a causalidade é necessária para a percepção dos objetos. As demais categorias estabelecidas por Kant são completamente dispensáveis. Nesta seção examinaremos como Schopenhauer justifica essa tese que constitui sua verdadeira revolução epistemológica.

Até aqui, procuramos esclarecer como opera a lei de causalidade e, para tanto, foi necessário compreender antes o intuir via entendimento e sua relação com o princípio de razão suficiente. Em síntese, a causalidade, para Schopenhauer, é: 1) a união das formas de espaço e tempo; 2) a matéria; 3) a atuação de um objeto sobre outro. A mais simples representação de algo depende da lei de causalidade. Isso se verifica em cada uma de nossas percepções sensoriais desde que se compreenda o caráter imediato da remissão de um efeito àquilo que o produz, sem o que o dado sensorial não seria "entendido", mas tomado como absurdo ou mesmo ilusório, tal como o som de uma trovoada em um claro dia de sol sem nuvens ou o ranger de uma porta se abrindo enquanto permanece fechada diante de nossos olhos. Portanto, a causalidade não deixa de atuar mesmo na mais imediata das percepções, a visual, na qual a distinção entre causa e efeito sequer é considerada, uma vez que, ao abrirmos os olhos, instantaneamente, a luminosidade produz imagens em nós. Se não fosse pelo entendimento, essas imagens jamais poderiam ser projetadas em um espaço externo como objetos aos quais pertencem as qualidades percebidas, como forma, cor, extensão - em outras palavras, os

\footnotetext{
${ }^{16}$ CACCIOLA, A crítica da razão no pensamento de Schopenhauer, 41.

${ }^{17}$ A propósito, toda matéria é representada intuitivamente como causa de uma modificação nos órgãos dos sentidos ou na configuração de outros objetos, não tendo ela mesma uma causa para a sua existência, podendo, nesse sentido, ser chamada de "substância".
} 
sentidos consistem apenas em afecções do sentido interno, não bastando à representação de objetos reais no espaço ${ }^{18}$.

Uma questão que pode parecer menor, porém, é de extrema relevância e, portanto, não pode ser esquecida ao se ler a Crítica da razão pura é, conforme Schopenhauer, o sacrifício da tese kantiana às amarras impostas pela arquitetônica conceitual, de maneira que Kant de modo algum se permite abandonar a simetria ao apresentar sua doutrina do conhecimento, submetida a todo momento ao formato de tábuas. Assim sendo, as postulações kantianas, a saber, que da tábua dos juízos deduz-se a tábua das categorias, que de conceitos puros originam-se conceitos empíricos, são, como bem enfatiza Cacciola - tanto na sua dissertação quanto em Schopenhauer e a questão do dogmatismo -, produto de uma mente preocupada de modo exacerbado com a simetria, ou ainda, tudo isso seria reflexo do que Schopenhauer chama de uma "arquitetura gótica" intrínseca ao modelo kantiano de sistematização. Para ilustrar o ponto, trazemos aqui uma das passagens da Crítica na qual Kant dá oportunidade à crítica de Schopenhauer:

Desse modo surgem precisamente tantos conceitos puros do entendimento, que se referem a priori a objetos da intuição em geral, quantas eram na tábua anterior as funções lógicas em todos os juízos possíveis. Com efeito, através de tais funções o entendimento é completamente exaurido e sua faculdade inteiramente medida. Seguindo Aristóteles, denominaremos tais conceitos categorias na medida em que nossa intenção, em princípio, identifica-se com a de Aristóteles, se bem que se afaste bastante dela na execução ${ }^{19}$.

Além disso, conforme Cacciola, deduzir a tábua das categorias a partir da tábua dos juízos é já uma demonstração da inversão kantiana sobre qual é a faculdade prioritária - se a de intuir ou a de abstrair - e tal inversão Schopenhauer condena como sendo um dos erros fundamentais da teoria crítica. Afinal, se juízos são compostos por conceitos, por que partir de formas de juízos para determinar conceitos puros? Ou, dito de outro modo, apesar de os conceitos puros não terem sido abstraídos da experiência, mas, pelo contrário, deverem conformar os dados sensíveis a fim de determiná-los como objetos de experiência, permanecem consistindo em abstrações obtidas por análise formal de juízos dados ${ }^{20}$. Por exemplo, ainda que a causalidade seja conhecida a priori, conforme admite Schopenhauer, é muito diferente dizer que o conceito de "causalidade" não tenha sido abstraído da experiência de efeitos, ao passo que, a relação de causalidade não pode ser ela mesma objeto de nenhuma experiência possível, não passando de abstração. Portanto, Schopenhauer parece estar justificado ao dizer que se trata de uma inversão arbitrária deduzir um conceito puro de "causalidade" a partir da mera forma de um juízo de relação, como se fosse possível explicar - Kant ora admite não sê-lo, ora diz não ser necessário fazê-lo - como é possível conhecer a priori conceitos puros ou formas de juízo - na verdade, trata-se de uma questão transcendente e alheia ao procedimento analítico que toma as formas de juízos como condições dadas do pensamento em geral. O mesmo se dá com as demais categorias. Conforme Cacciola: "A dedução das categorias a partir da 'tábua dos juízos lógicos' é impugnada por Schopenhauer que vê nesta dedução a inversão da hierarquia entre representações intuitivas e abstratas. Kant, ao fazer derivar das 'formas do juízo' a condição do conhecimento dos objetos, teria privilegiado o pensar em detrimento do intuir" ${ }^{21}$.

Ao menos duas estranhas consequências parecem surgir a partir do exposto. Em primeiro lugar, os doze conceitos puros do entendimento são assumidos por Kant como necessários porque não se poderia abrir mão da tábua dos juízos, mas esses juízos não podem ser formulados sem os conceitos que deles são deduzidos. Por exemplo, a relação "Se... então", pela qual se exprime um

\footnotetext{
${ }^{18}$ Para uma análise profunda da questão, em virtude de suas amplas notas explicativas, sugerimos a leitura dos capítulos 2 e 6 do Tomo II de $O$ Mundo, conforme tradução que consta nas referências bibliográficas: Schopenhauer, 2012.

${ }^{19}$ KANT, Crítica da razão pura, 108 [B 105].

20 “Antes quero apenas adiantar a explicação das categorias. São conceitos de um objeto em geral mediante os quais a sua intuição é considerada determinada no tocante a uma das funções lógicas de juízos" (KANT, Crítica da razão pura, 120 [B 129]).

${ }^{21}$ CACCIOLA, A crítica da razão no pensamento de Schopenhauer, 62.
} 
juízo hipotético, só pode ser determinada se temos algo a que se atribua os conceitos de "condicionante" e "condicionado", que devem ser pressupostos em todo juízo hipotético. Em termos lógicos, também cabe observar que, em nome da arquitetônica, uma só categoria tem de dar conta de relações tão diversas quanto a de "causa" e "implicação", expressas por Kant sob a rubrica "causalidade e dependência (causa e efeito)". De resto, Schopenhauer também observa que juízos hipotéticos e disjuntivos nada mais são do que relações entre dois ou mais juízos categóricos. Em segundo lugar, Kant atribui à faculdade de entendimento funções exclusivas da faculdade racional, de abstração, até porque privilegia esta em detrimento da faculdade intuitiva. Isso se verifica, conforme já apontado, pelo fato de que o formalismo inerente ao método analítico desconsidera que o pensamento não é possível na ausência de objetos determinados em conceitos abstraídos da intuição e que, portanto, suas regras dizem respeito apenas às leis do pensamento, que Schopenhauer tematiza sob a rubrica de "princípio de razão do conhecer", não ao modo como esses objetos são determinados como objetos de uma experiência possível. Assim se compreende o teor da crítica schopenhaueriana à epistemologia de Kant ao acusá-la de postular arbitrários contrassensos. Encontramos também na leitura de Schopenhauer e il fondamento della conoscenza, de Danilo Ciolino, apoio textual para a afirmação de que a defesa kantiana da necessidade de doze categorias ocorre pelo fato de que ele não confere ao entendimento o mesmo papel que lhe atribui Schopenhauer, o que implica na total diferença entre se tomar a causalidade como um princípio de razão que fundamenta a intuição de objetos sensíveis ou como um mero conceito de relação.

Nas palavras de Ciolino, temos, adicionalmente, esclarecido que não se trata apenas de tomar as palavras de Schopenhauer ao pé da letra quando diz que conservou somente uma das doze categorias, até porque ele não admite, ao menos a partir de $O$ Mundo, a participação de nenhuma categoria ou elemento discursivo, nenhum pensamento, no que concerne à determinação de objetos sensíveis como tais:

No que diz respeito a este tópico a leitura resulta frequentemente enganadora, geralmente relatada por manuais populares, em conformidade com os quais Schopenhauer teria simplesmente rejeitado onze das doze categorias kantianas, mantendo apenas a de causalidade, não levando em consideração contemporaneamente o fato de que aquilo que propriamente Schopenhauer tem in primis rejeitado é tanto uma concepção discursiva do entendimento quanto uma interdependência funcional entre sensibilidade intuitiva e entendimento discursivo, conforme a hipótese de Kant. Toda a discussão sobre o princípio de razão é inerente ao proprium de uma faculdade específica, própria do homem, a razão, que Schopenhauer demonstra ser não essencial em relação às condições de possibilidade da experiência, mas que, pelo contrário, torna o conhecimento da realidade, intelectualmente intuído e empiricamente funcional, um objeto de conhecimento racional: em resumo, a razão é o que torna o produto do conhecimento, intuitivo e particular, um saber racional, abstrato e geral ${ }^{22}$.

Portanto, o princípio de razão consiste no modo como devem ser pensados os objetos do conhecimento possível de acordo com seu fundamento conhecido a priori. Desse modo, Schopenhauer não "joga fora" pura e simplesmente as doze categorias kantianas, mas, antes, demonstra que, de sua perspectiva epistemológica, aquilo a que se refere onze delas não é de modo algum necessário ao conhecimento de objetos pelo entendimento, dado que, nas representações do mundo à nossa volta, apenas a causalidade atua. Inclusive, quanto a esse último ponto, Schopenhauer, como um crítico atento, não deixa de ter apoio no próprio texto de Kant:

Ora, se todavia abstraio da forma constante de minha intuição interna, do tempo, como condição a priori sob a qual ligo o múltiplo de uma intuição em geral tal unidade sintética é a categoria de causa, pela qual se a aplico à minha sensibilidade, determino no tempo em geral, segundo a sua relação, tudo o que

${ }^{22}$ CIOLINO, Schopenhauer e il fondamento della conoscenza, 91-92. 
acontece. Portanto, a apreensão encontra-se num tal evento, por conseguinte este mesmo, segundo a percepção possível, sob o conceito de relação entre efeitos $e$ causas, ocorrendo o mesmo em todos os demais $\operatorname{casos}^{23}$.

Para Kant, no entanto, as categorias somente poderiam ser dispensáveis no caso de uma inteligência divina, cujo entendimento poderia ter a capacidade de intuir. No §21 da Analítica Transcendental, Kant afirma:

Na prova acima, só não pude abstrair de uma parte a saber, de que o múltiplo da intuição tem que ser dado ainda antes e independente da síntese do entendimento; de que modo, porém, fica aqui indeterminado. Com efeito, se eu quisesse pensar um entendimento que intuísse ele mesmo (como por exemplo um entendimento divino, que não se representasse objetos dados, mas mediante cuja representação os próprios objetos fossem ao mesmo tempo dados ou produzidos), então as categorias não teriam significação alguma no tocante a um tal conhecimento ${ }^{24}$.

A partir do que nossa análise pretendeu demonstrar até aqui, essa faculdade de entendimento que Kant não se permite admitir no caso do conhecimento humano não precisa ser de ordem divina. Conforme vimos em nossa primeira seção, Kant pretendia apenas refutar a possibilidade de uma intuição intelectual por meio da qual pudéssemos pensar objetos que se encontram além da possibilidade de experiência, a saber, transcendentes, e nisso é seguido por Schopenhauer com rigor. Em vez de tais objetos transcendentes, Kant, todavia, advoga a necessidade de um objeto transcendental como aquilo para o que devem apontar os dados da intuição, que, como tais, são indeterminados quanto à sua causa. A causa, portanto, só pode ser pensada - não sendo ela mesma dada na sensibilidade - por uma faculdade de entendimento pela qual o múltiplo da intuição recebe a unidade de uma síntese. Por sua vez, de acordo com Kant, uma inteligência, por nós completamente desconhecida, cujas percepções não fossem limitadas pelas formas de espaço e tempo - por isso denominada "divina" -, supostamente teria acesso imediato às coisas em si tal como são, não havendo, para ela, distinção entre o objeto em si e sua aparência na representação. Mas é precisamente aqui que Schopenhauer aponta para a inconsequência de Kant, explicitando o caráter realista dessa manobra e, portanto, uma contradição no seio da Crítica da razão pura. Nas palavras de Cacciola:

Para ele [Schopenhauer] o engano de Kant é o de distinguir aqui representação e objeto: ou seja, se essa representação vem "de fora", já pressupõe o espaço e, portanto, a causalidade, e já é mesmo um objeto [...]. Para ele, é da intromissão de conceitos e do pensar nesta operação que resulta a "mistura malsã" kantiana entre conhecimento intuitivo e abstrato e, portanto, entre as classes de representações intuitivas referidas ao entendimento e as representações abstratas próprias à razão ${ }^{25}$.

Ao derivar a exigência de coisas em si como causas ou origens incognoscíveis das representações, Kant admite uma espécie de dualismo, ao mesmo tempo em que contraria a correta descoberta de que não há aplicação válida da lei de causalidade a coisas em si, apenas entre fenômenos. Em resumo, as duas últimas citações são cruciais por exporem a injustificável postulação de dois objetos, um deles irrepresentável, transcendental.

Como também vimos, Schopenhauer, seguindo as diretrizes do próprio Kant, recusa que algo irrepresentável seja um objeto propriamente dito, dando, portanto, sentido diverso à sua coisa em si. Salienta, todavia, que a identidade entre o objeto percebido e a representação não significa que se trata de uma relação de correspondência entre dois objetos, mas, pelo contrário, recusa que haja qualquer objeto propriamente dito fora da representação. Superado o falso pressuposto dualístico de Kant, ainda pautado na distinção entre conteúdos na mente e objetos fora dela, cujo

\footnotetext{
${ }^{23}$ KANT, Crítica da razão pura, 136 [B 163].

${ }^{24}$ KANT, Crítica da razão pura, 127 [B 145].

${ }^{25}$ CACCIOLA, A crítica da razão no pensamento de Schopenhauer, 44-45.
} 
pensamento é impossível, permanece impossível ao entendimento o conhecimento das coisas em si mesmas, além do princípio de razão, de maneira que um entendimento que intui não implica que o mesmo consista em uma faculdade divina de conhecimento. Por conseguinte, essa faculdade que Kant pensa ser possível apenas a Deus ou a qualquer inteligência puramente racional, destituída de sensibilidade, é proclamada por Schopenhauer como uma faculdade impensável e de que não se tem notícia, haja vista a ironia com que Schopenhauer se refere à intuição intelectual schellinguiana.

Feito esse esclarecimento e essa contextualização, retornemos ao sentido da desconsideração das demais categorias kantianas por Schopenhauer. Na Crítica da filosofia kantiana, Schopenhauer analisa exaustivamente cada uma das categorias com o intuito de demonstrar que onze categorias são dedutíveis do conhecimento a priori da causalidade, dado que é essa a única função que o entendimento de fato desempenha, aplicando esse conhecimento às afecções dos sentidos. As categorias modais de possibilidade, existência e necessidade, por exemplo, são obtidas a partir da lei de causalidade na medida em que tudo o que é efetivo - na medida em que é percebido como algo que produz efeito ou decorre de uma causa - é também necessário e, portanto, existência e necessidade podem ser consideradas sinônimos, visto que, se algo existe de fato, é impossível para ele não existir - logo, é necessário - e, se existe, é porque sua existência é possível. Por diferentes que sejam os propósitos dessas categorias no contexto da Crítica da razão pura, por exemplo, nos Postulados do Pensamento Empírico, o que Schopenhauer pretende mostrar é que cada tríade pode ser reduzida a uma única categoria de seu grupo e esta, por sua vez, pode ser remetida à causalidade. Dito brevemente, se as causas necessárias produtoras de um efeito não ocorrem, o efeito não se segue, não havendo lugar para que nenhuma outra categoria exerça seu papel, de maneira que toda representação de objetos sensíveis supõe a causalidade como determinação suficiente, enquanto as categorias se tornam, segundo a expressão schopenhaueriana, "janelas cegas". Embora o presente artigo não comporte a reprodução detalhada de toda a exposição de Schopenhauer, à qual remetemos o leitor, destacamos um trecho em que o assunto é exposto de modo bastante coeso nas próprias palavras do autor:

De um conhecimento propriamente dito do entendimento, em meu sentido, nasce ademais o juízo categórico só lá onde, através deste, exprime-se uma causalidade; esse também é o caso de todos os juízos que indicam uma qualidade física, pois, quando digo "este corpo é pesado, duro, fluido, verde, alcalino, orgânico e assim por diante", isso sempre indica seu fazer-efeito, portanto um conhecimento que é possível apenas pelo entendimento puro [...]. Porém mais adiante tornarei evidente que o conceito de substância não tem nenhum outro verdadeiro conteúdo senão o do conceito de matéria. Acidentes, entretanto, são sinônimos de tipos de efeito, de modo que o suposto conhecimento de substância e acidente é sempre ainda o conhecimento de causa e efeito do entendimento puro (W I, 543-544 [trad. br. 530531]).

Assim se verifica de que modo Schopenhauer confere à causalidade o verdadeiro status de "pureza", não de um conceito, o que, para ele, consiste em uma contradictio in terminis, mas porque ela opera na origem mesma do ato de conhecer, sem o que nenhuma intuição é possível, ou seja, a consciência de um objeto efetivamente presente aos sentidos. Ao mesmo tempo, a casualidade é suficiente. Assim, as categorias se tornam completamente dispensáveis à percepção. O tripé tempo-espaço-causalidade permite por si só que haja representações intuitivas, conhecimento empírico, ou ainda, tornam o objeto completamente "real", efetivo, existente e necessário, ao menos como objeto conhecido, não se tratando aqui da realidade da coisa em si, apenas da realidade do fenômeno objetivo relativamente ao sujeito do conhecimento. $\mathrm{Na}$ Dissertação de Cacciola, podemos ler:

É a partir dessas considerações que Schopenhauer rejeita toda doutrina das categorias, que é exposta por Kant na "Analítica Transcendental". Sendo o entendimento uma faculdade intuitiva, não lhe "cabem conceitos puros", mas sua única forma é a lei da causalidade que [...] não é um conceito a priori, mas um dos 
elementos subjetivos que compõem a representação, que torna possível explicar a relação da sensação [interna, como estado sucessivo no tempo] à sua causa externa [segundo a forma do espaço]. [...] Desde que a causalidade é a única forma do entendimento, visto como faculdade intuitiva, as "onze categorias restantes" são, para Schopenhauer, "janelas cegas" 26 .

Como bem enfatiza Cacciola, essa obra de Kant de infiltrar o "pensar" no "intuir" - que ele realiza ao aplicar os conceitos puros do entendimento a uma intuição dada - não permite que compreendamos qual é de fato a origem dessa intuição porque, como enfatiza Schopenhauer, Kant deixa inexplorada a gênese da intuição empírica pelo fato de que também a considera "um dado" e, assim, permite a confusão com a intuição sensível. A razão disso, além da recusa por parte de um entendimento capaz de intuir, é que ele também toma a faculdade de intuição como mera receptividade, tratando-a de modo análogo ao tratamento que Schopenhauer dispensa às meras sensações, sendo também este um ponto que produz grande confusão entre os intérpretes, a qual, todavia, o espaço nos impede de aprofundar aqui. A única diferença que Kant faz nesse sentido, embora não seja pequena, é que a faculdade de intuição imporia as formas de tempo e espaço aos dados sensoriais, tornando-se ela mesma um mero dado, mas, como insiste Schopenhauer, isso não basta para que se intua objeto algum.

\section{Agradecimentos}

Dedico este artigo à professora Dra. Maria Lúcia Cacciola e ao professor Dr. Domenico M. Fazio. A ela pela inspiração, apoio e acesso ao seu trabalho seminal para os estudos schopenhauerianos no Brasil. A ele pela recepção no Centro Interdipartimentale di ricerca su Arthur Schopenhauer e la sua scuola em Lecce, o que permitiu o aprofundamento de minha pesquisa e a escrita deste artigo, como um de seus resultados.

\section{Referências}

CACCIOLA, M. L. O. M. A crítica da razão no pensamento de schopenhauer. Dissertação (Mestrado em Filosofia) - Universidade de São Paulo. 95f. São Paulo, 1981.

CACCIOLA, M. L. O. M. Schopenhauer e a crítica da razão: a razão e as representações abstratas. Discurso, Sao Paulo, n. 15, 91-106, jul-dez. 1983. Disponível em: <http://www.revistas.usp.br/discurso/article/view/37913>. Acesso em: 25 jul. 2020.

CACCIOLA, M. L. O. M. Schopenhauer e a questão do dogmatismo. São Paulo: EDUSP, 1994.

CIOLINO, D. Schopenhauer e il fondamento della conoscenza: dalle aporie kantiane ai lineamenti di una fenomenologia trascendentale. Padova: CLEUP, 2014.

DEBONA, V. Schopenhauer e as formas da razão: o teórico, o pratico e o ético-místico. São Paulo: Annablume, 2010.

FONSECA, E. R. Uma estreita passagem: o conceito de corpo nas obras de Schopenhauer e Freud. Curitiba: UFPR, 2016.

KANT, I. Crítica da razão pura. Trad. Valério Rohden e Udo Baldur Moosburger. São Paulo: Nova Cultural, 1996.

LAZZARETTI, L. P. Resenha de "Uma estreita Passagem: o conceito de corpo nas obras de Schopenhauer e Freud”, de Eduardo Fonseca. Voluntas, Rio de Janeiro, v. 7 n. 2, p. 153-159, jul-

${ }^{26}$ CACCIOLA, A crítica da razão no pensamento de Schopenhauer, 60-61. 
dez. 2016. Disponível em: <https://periodicos.ufsm.br/voluntas/article/view/33728>. Acesso em: 25 jul. 2020.

LEBRUN, G. O subsolo da Crítica: uma conferencia inédita de Lebrun sobre Kant. Discurso, Sao Paulo, v. 46, n. 2, p. 53-84, jul-dez. 2016. Disponível em: <http://www.revistas.usp.br/discurso/article/view/123669>. Acesso em: 25 jul. 2020.

LEFRANC, J. Compreender Schopenhauer. 5. ed. Petrópolis: Vozes, 2011.

SALVIANO, J. O. S. O fundamento epistemológico da metafísica da vontade de Arthur Schopenhauer. Trans/Form/Ação, São Paulo, v. 32 n. 2, 101-118, jul-dez. 2009. Disponível em: <http://www2.marilia.unesp.br/revistas/index.php/transformacao/article/view/1010>. Acesso em: 25 jul. 2020.

SCHOPENHAUER, A. Crítica da filosofia kantiana. Trad. M. L. M. e O. Cacciola. In: Os Pensadores. Schopenhauer. São Paulo: Abril Cultural, 1997.

SCHOPENHAUER, A. Tradução dos capítulos 2 e 6 do Tomo II (Suplementos) de O Mundo como Vontade e Representação (Para a Doutrina do Conhecimento Intuitivo, ou do Entendimento (Cap.2) e Para a Doutrina do Conhecimento Abstrato, ou Racional (Cap.6)). Trad. Dax Moraes. Voluntas, Rio de Janeiro, v. 3, n. 1-2, p. 326-347, 2012. Disponível em: <https://periodicos.ufsm.br/voluntas/article/view/34043>. Acesso em: 25 jul. 2020.

SCHOPENHAUER, A. Sulla quadruplice radice del principio di ragione sufficiente. A cura di Sossio Giametta. Milano: BUR Rizzoli, 2014a.

SCHOPENHAUER, A. O mundo como vontade e representação. Tomo II: Complementos. Trad. Eduardo Ribeiro da Fonseca. Curitiba: UFPR, 2014b. 2 v.

SCHOPENHAUER, A. O mundo como vontade e como representação: primeiro tomo. Trad. Jair Barboza. São Paulo: UNESP, 2015a.

SCHOPENHAUER, A. O mundo como vontade e como representação: segundo tomo. Trad. Jair Barboza. São Paulo: UNESP, 2015b.

\section{Bibliografia adicional consultada}

CACCIOLA, M. L. O. M. A questão do finalismo na filosofia de Schopenhauer. Discurso, São Paulo, n. 20, p. 77-98, jan-abr. 1993. Disponível em: <http://www.revistas.usp.br/discurso/article/view/37957>. Acesso em: 25 jul. 2020.

CACCIOLA, M. L. O. M. Prólogo: Schopenhauer é um verdadeiro discípulo de Kant? Aurora, Curitiba, v. 30 n. 49, p. 8-17, jan-abr. 2018. Disponível em: <https://periodicos.pucpr.br/index.php/aurora/article/view/23521>. Acesso em: 25 jul. 2020.

CAYGILL, H. Dicionário Kant. Rio de Janeiro: J. Zahar, 2000.

FAZIO, D. M.; KOßLER, M.; LÜTKEHAUS, L. (Org.). 2009. La scuola di Schopenhauer: testi e contesti. Lecce: Pensa MultiMedia, 2009.

KAMATA, Y. Ideia platônica e o mundo intuitivo em Schopenhauer. Trad. L. L. Valente. Voluntas, Rio de Janeiro, v. 8 n. 2, p. 150-164, jul-dez. 2017. Disponível em: <https://periodicos.ufsm.br/voluntas/article/view/33654/18236>. Acesso em: 25 jul. 2020.

KAMATA, Y. A recepção de Kant pelo jovem Schopenhauer em "Sobre a quádrupla raiz do princípio de razão suficiente". Aurora, Curitiba, v. 30 n. 49, p. 236-254, jan-abr. 2018. Disponível em: <https://periodicos.pucpr.br/index.php/aurora/article/view/23512>. Acesso em: 25 jul. 2020. 
KOßLER, M. "Um absurdo audacioso": intuição e conceito na crítica de Schopenhauer a Kant. Aurora, Curitiba, v. 30 n. 49, 159-172, jan-abr. 2018. Disponível em: <https://periodicos.pucpr.br/index.php/aurora/article/view/23572>. Acesso em: 25 jul. 2020.

PERNIN, M.-J. Schopenhauer: decifrando o enigma do mundo. Rio de Janeiro: J. Zahar, 1995. 